\title{
Efficacy of iron-fortified Ultra Rice in improving the iron status of women in Mexico
}

\author{
Christine Hotz, Maribel Porcayo, Germán Onofre, Armando García-Guerra, Terry Elliott, \\ Shirley Jankowski, and Ted Greiner
}

\begin{abstract}
Background. Universal fortification of staple foods with iron has been widely promoted as a cost-effective strategy to reduce iron deficiency in developing-country populations. Nonetheless, relatively few efficacy trials have been reported to date to demonstrate impact on iron status. The Ultra Rice technology provides a means of delivering fortificant iron via rice.

Objective. The objective of this study was to test the efficacy of rice fortified with microencapsulated, micronized iron pyrophosphate to improve the iron status of women in Mexico in a randomized, controlled intervention trial.
\end{abstract}

Methods. Nonpregnant, nonlactating women 18 to 49 years of age were recruited from six factories. The women received a daily portion of cooked rice 5 days per week for a period of 6 months, before and after which iron status indicators were determined in venous blood samples.

Results. The average intake of iron from the fortificant was $13 \mathrm{mg} /$ day. Mean plasma ferritin concentration and estimated body iron stores were significantly higher, and transferrin receptors were lower, in the iron-fortified rice group following the intervention. Mean hemoglobin concentration also increased in the treatment group, but the increase was significant only when the analysis was restricted to those with baseline hemoglobin $<12.8 \mathrm{~g} / \mathrm{dL}$. The absolute reduction in anemia and iron deficiency was 10.3 and 15.1 percentage points, respectively. Total

Christine Hotz was affiliated with the Centro de Investigación en Nutrición y Salud, Instituto Nacional de Salud Pública, Cuernavaca, Morelos, Mexico, at the time of the study and is now affiliated with the International Food Policy Research Institute, Washington, DC; Maribel Porcayo, Germán Onofre, and Armando García-Guerra are affiliated with the Centro de Investigación en Nutrición y Salud; Terry Elliott and Ted Greiner are affiliated with the Program for Appropriate Technology in Health (PATH), Seattle, Washington, USA; Shirley Jankowski is an independent consultant

Please direct queries to the corresponding author: Christine Hotz, HarvestPlus, c/o International Food Policy Research Institute, 2033 K Street, NW, Washington DC 20006-1002 USA; email c.hotz@cgiar.org. iron intake from fortificant was a significant covariate of change in body iron stores. The overall prevalence of anemia was reduced by $80 \%$.

Conclusions. Fortification of rice with iron using this technology is an efficacious strategy for preventing iron deficiency.

Key words: Anemia, ferric pyrophosphate, fortification, iron deficiency, Mexico, rice

\section{Introduction}

Iron deficiency is the most widespread nutritional disorder in the world and is also the most important cause of anemia [1]. Iron deficiency causes poor health, leading to impaired cognitive performance, growth, and work performance as well as increased risk of infections, perinatal mortality, low birthweight, and premature birth [2-6]. Among women, anemia contributes to about $20 \%$ of all maternal deaths in Africa and Asia, and productivity losses due to iron deficiency are estimated at $0.9 \%$ of the gross domestic product in developing country regions [7].

The fortification of wheat flour with iron has been widely promoted as a cost-effective strategy to control iron deficiency [8]. However, rice is an important staple food for more than half of the world's population. Unfortunately, polished rice has a very low iron content and is technically more difficult to fortify than wheat flour. Coating rice grains directly with iron compounds has been considered, but this strategy may be limited because of the large loss of iron after washing and cooking the rice [9]. Alternative technologies for fortifying rice have therefore been developed, including that used for Ultra Rice (a registered trademark of Bon Dente International in the United States). This technology uses a cold extrusion process to manufacture simulated rice grains from rice flour and added micronutrients, which are then added as a premix to regular polished rice. Ultra Rice fortified with vitamin A has been shown 
efficacious for improving dark adaptation among pregnant Nepali women with night-blindness [10].

Iron-formula Ultra Rice uses ferric pyrophosphate, a colorless, nonreactive form of iron commonly used in milk, yogurt, and other foods in which taste and color must be maintained. Specifically, a commercial microencapsulated and micronized form of ferric pyrophosphate called SunActive (a registered trademark of Taiyo International, Minneapolis, MN, USA) is used. Fortification of rice with SunActive by this extrusion technology has been found to result in a cooked product with acceptable sensory characteristics $[11,12]$.

Although poorly soluble compounds such as ferric pyrophosphate tend to have a lower relative bioavailability than more soluble compounds, reducing particle size can at least partially compensate, as shown in a previous study in rats (e.g., from a mean particle size of $21 \mu \mathrm{m}$ to $2.5 \mu \mathrm{m}$ [13]) and for elemental iron in humans [14]. Encapsulation can help to maintain particle size by preventing agglomeration of the small particles, but Wegmüller et al. [13] found that encapsulation resulted in a reduced relative bioavailability of micronized ferric pyrophosphate. The SunActive form of ferric pyrophosphate has been shown to have a similar bioavailability as ferrous sulfate when added to wheat- and milk-based infant cereal and a yogurt drink [15]. However, encapsulated, micronized ferric pyrophosphate provided in a fortified extruded rice product was found to have a relative bioavailability of only $24 \%$ [16], which may be partly attributed to the difference in food matrix but also to the larger mean particle size of the compound $(0.77 \mu \mathrm{m})$ used in that study.

The addition of micronized ferric pyrophosphate (mean particle size, $2.5 \mu \mathrm{m}$ ) to iodized salt was shown to be efficacious in reducing iron deficiency and anemia in a study of Moroccan schoolchildren [17]. In a similar study using the same formulation, only a small reduction in iron deficiency and no net impact on anemia were observed among Ivoirian children [18]. However, in the latter study, the impact may have been confounded by high rates of malaria and concurrent micronutrient deficiencies, such as vitamin $B_{12}$ deficiency. When micronized ferric pyrophosphate (mean particle size, $2.5 \mu \mathrm{m}$ ) was added to an extruded, fortified rice product similar to Ultra Rice, it resulted in a significant improvement in iron stores among Indian schoolchildren, as determined by serum ferritin and transferrin receptors, and a nonsignificant reduction in the prevalence of anemia [19].

The commercial SunActive form of ferric pyrophosphate has a mean particle size $(0.3 \mu \mathrm{m})$ that is substantially lower than that of the micronized form used in previous efficacy trials $(2.5 \mu \mathrm{m})$, and it is microencapsulated; thus, it is also likely to be more expensive. Its use in staple food fortification has not yet been evaluated in an efficacy trial. The objective of this study was to determine the efficacy of Ultra Rice fortified with microencapsulated, micronized ferric pyrophosphate (SunActive) to improve iron status among women in Mexico.

\section{Subjects and methods}

This was a randomized, blinded-to-participants, placebo-controlled feeding trial of 6 months' duration, comparing the biochemical iron status of participants consuming iron-formula Ultra Rice with that of a control group receiving unfortified rice. This study was approved by the research, ethics, and biosecurity commissions of the Instituto Nacional de Salud Pública, Cuernavaca, Mexico, and the Human Subjects Protection Committee of the Program for Appropriate Technology in Health (PATH), Seattle, Washington, USA.

\section{Study population and recruitment}

The study sample consisted of nonpregnant, nonlactating women 18 to 49 years of age with moderate to low hemoglobin concentrations. The participants were recruited from six factories in Morelos State, Mexico, that were located between 1 and $25 \mathrm{~km}$ from Cuernavaca. During the screening procedure, hemoglobin concentration was determined in capillary blood samples from consenting women. Women with altitudeadjusted [20] hemoglobin concentrations between 10.5 and $13.5 \mathrm{~g} / \mathrm{dL}$ were included in the intervention study. Women with adjusted hemoglobin concentrations $\geq 13.5 \mathrm{~g} / \mathrm{dL}$ were excluded; those with hemoglobin concentrations $<10.5 \mathrm{~g} / \mathrm{dL}$ were excluded and referred for iron therapy. Also excluded were women who were currently taking, or were planning to take, iron supplements in the next 6 months or were planning to discontinue employment at their workplace in the next 6 months. The remaining women were invited to participate in the trial. Informed, written consent was obtained from all those agreeing to participate.

Upon enrollment, each woman was assigned a unique, consecutive identification number. These numbers were then randomly assigned by computer to one of two groups (control or iron-fortified rice). The women did not know to which group they were assigned. Informed, written consent was obtained from all women who enrolled.

\section{Preparation of the extruded rice}

The iron fortificant used in this study was microencapsulated, micronized ferric pyrophosphate, which is marketed as SunActive iron. The iron-fortified rice was prepared by first adding this iron fortificant and other stabilizing ingredients to rice flour. Dough prepared from this mixture was extruded (using the same extrusion process used to make pasta), cut to form 
rice-shaped grains, and then dried. The extruded grains were manufactured by the Department of Chemical Engineering and Applied Chemistry at the University of Toronto, Canada.

\section{Feeding trial intervention}

The fortified rice was formulated to provide $20 \mathrm{mg}$ of iron per daily portion during 6 months, which approximates the recommended daily intake for iron for nonpregnant, nonlactating women in Mexico (21 $\mathrm{mg}$ ) [21]. The fortified grains were mixed directly with dry, locally obtained rice. For the first 3 months of the study, the fortified grains were added at a proportion of 2:100 (weight/weight), and each daily portion of rice consisted of $75 \mathrm{~g}$ of dry rice. Because of plate wastage observed during the first 3 months, for the second half of the feeding period the blend rate was doubled to $4: 100$ and the daily quantity of dry rice was halved to $37 \mathrm{~g}$ per person, thus holding the amount of iron fortificant per daily portion constant. The control and fortified rice containers were color coded for premixing, cooking, and packing.

Rice was prepared daily in a central kitchen with a standard recipe that was varied from day to day by using different combinations of one to three cooked vegetables (broccoli, carrot, cauliflower, garlic, green bean, onion, parsley, pea, pepper, potato, sweet corn, and tomato) and seasonings. Portions were weighed by project personnel and packed in individual plastic containers labeled with the participant's name and study identification number. The containers were delivered to the factories on Monday through Friday each week, except for days when labor was suspended, and the rice was eaten as an accompaniment to the midday meal in the cafeteria where the women would normally eat.

Because of the large number of different lunch shifts, it was not feasible for project staff to monitor consumption of the rice. However, the women were instructed not to share their rice with other coworkers, not to change containers with other participants, and not to throw away any leftover rice. Unannounced site visits indicated that compliance with these requests was good. After the last lunch break shift, the containers were collected and each one was weighed to record any leftover portion of rice. These records were used to monitor compliance and later to calculate the amount of additional iron ingested throughout the study by each individual in the fortified-rice group.

\section{Sample and data collection}

Baseline and final (6 months) data collection consisted of venous blood collection for biochemical analysis and pregnancy testing. At midstudy (3 months), capillary blood samples were obtained by fingerprick for hemoglobin determination and urine samples were obtained for pregnancy testing. All samples were collected at the worksite in designated areas by trained fieldworkers. Whole blood drawn from the antecubital vein was collected into heparinized, evacuated blood-collection tubes. Plasma was separated in the field with the use of a portable centrifuge $(20$ minutes at $3,500 \mathrm{~g})$ and transferred to labeled cryotubes. These were stored on ice and shipped daily to the nutrition laboratory at the Instituto Nacional de Salud Pública, where they were stored at $-70^{\circ} \mathrm{C}$ until the time of analysis.

Pregnancy tests on urine samples were also performed throughout the study at the participant's request. Women who became pregnant at any time during the study, who reported taking iron supplements, or who had very low hemoglobin concentrations at midstudy $(<10 \mathrm{~g} / \mathrm{dL})$ were withdrawn from the study, provided with a 1-month supply of iron tablets $(60 \mathrm{mg} /$ day), and referred to a local health facility for follow-up. All women who had anemia at the end of the study received the same treatment and referral.

\section{Biochemical determinations}

Blood hemoglobin concentration was determined at the time of venous blood collection with the use of microcuvettes and a portable photometer (HemoCue). Hemoglobin was routinely determined in duplicate; duplicates with a difference of $\geq 0.5 \mathrm{~g} / \mathrm{dL}$ were corroborated by a third determination. Hemoglobin determinations made using this equipment were previously validated in the Mexican population [22]. Pregnancy was determined with the use of reactive strips (Hycel Gestastrip Combo) measuring human chorionic gonadotropin $( \pm 20 \mathrm{mU} / \mathrm{mL})$. Plasma ferritin and soluble transferrin receptors were measured by ELISA using commercial kits (Dade Behring), and C-reactive protein was determined by nephelometry (Nephelometer 100, Dade-Behring). Baseline and postintervention samples from the same subject were paired and analyzed in the same run. The interassay coefficients of variation obtained for an internal standard during the analyses for this study were $3.3 \%$ for serum ferritin, $3.9 \%$ for serum transferrin receptors, and $5.3 \%$ for $\mathrm{C}$-reactive protein. For each of these assays, all values for the low, medium, and high commercial standards fell within the certified range.

For this study, anemia was defined as a hemoglobin concentration $<12.2 \mathrm{~g} / \mathrm{dL}$; this cutoff was derived from the World Health Organization (WHO) [23] established cutoff point $(<12.0 \mathrm{~g} / \mathrm{dL})$ adjusted for average altitude of the study sites $(1,100 \mathrm{~m})$ with the use of a published equation [20]. Iron deficiency was defined as a plasma ferritin concentration $<12.0 \mu \mathrm{g} / \mathrm{L}$ [23] or a plasma transferrin receptor concentration $>8.5 \mathrm{mg} / \mathrm{L}$ [24]. Body stores of iron (in milligrams per kilogram of body weight) were estimated with the use of a published equation [25]. 


\section{Sample size}

The sample size calculation was based on change in hemoglobin concentration. Initial sample size calculations were based on the assumption of a $1 \mathrm{~g} / \mathrm{dL}$ change in hemoglobin levels and an associated standard deviation of $1.3 \mathrm{~g} / \mathrm{dL}$, representing a large effect size (Cohen's $f=0.40$ ) for analysis of variance. A large effect could be detected in a two-tailed test with $90 \%$ power and an alpha of $5 \%$ in an initial sample of 82 women. On the assumption of a $10 \%$ loss to follow-up, recruitment was targeted at 90 women per group. A previous study with a similar design showed a significant increase in hemoglobin concentration $(0.5 \pm 0.1 \mathrm{~g} / \mathrm{dL})$ among anemic women in Vietnam receiving $10 \mathrm{mg}$ of iron per day as NaFeEDTA added to fish sauce for 6 months [26]. On the basis of these results, the sample size of 82 per group suggested above would provide more than $99 \%$ power for the statistical comparison.

\section{Data management and statistical analysis}

All raw data were entered and managed in Microsoft Office Excel 2003, and statistical analyses were performed with SPSS, version 13.0 for Windows. Data on plasma ferritin, transferrin receptor, transferrin receptor:ferritin ratio, and C-reactive protein were transformed by the natural logarithm function before statistical analysis. For samples with measured values below the detection limits for the assay, a nominal value was used ( 1.0 for ferritin and 0.1 for transferrin receptor and C-reactive protein). In the case of elevated C-reactive protein $(>10.0 \mathrm{mg} / \mathrm{L})$, the ferritin value for that subject was omitted from further analysis. Univariate analysis of variance (ANOVA) and analysis of covariance (ANCOVA) were used to detect significant differences in iron-status indicators between the control and iron-fortified groups at baseline and postintervention. In the latter case, the corresponding biochemical indicator at baseline was included as a covariable. The proportions of anemic and iron-deficient subjects were compared between time points for each treatment group by logistic regression analysis, with baseline anemia or iron-deficiency status used as a covariate. Descriptive data are presented as adjusted means with $95 \%$ confidence intervals. Differences are considered significant if $p<.05$.

\section{Results}

The participation and dropout rates were tracked and the reasons for leaving the study were noted (fig. 1). Ten women left the study at 3 to 6 months postintervention for reasons other than pregnancy, but final venous blood samples were obtained and their data were included in the analysis. For analysis of ferritin concentrations and classification of iron deficiency, data were omitted for a total of 17 subjects because of elevated C-reactive protein concentrations (control, $n=$ 10 , and iron-fortified, $n=7$ ). There were no differences in characteristics of the enrolled women between the treatment and control groups at baseline (table 1).

Although acceptance was not studied directly, there was no indirect evidence of a detectable difference in acceptability of the fortified rice compared with the control rice. No complaints were received about the taste of the rice from women in either group, and the dropout rates from the control and iron-fortified groups were similar (fig. 1). Consumption of the rice was variable overall, but there was no significant difference in rice intake between the two groups (see data below), suggesting they were equally acceptable.

Preliminary analysis of the postintervention data indicated that the factory where the woman was employed was not a significant variable, so this was not considered in further analyses. For each iron-status indicator, the baseline status of the corresponding

TABLE 1. Baseline characteristics of Mexican women participating in a randomized, controlled efficacy trial of iron-fortified rice

\begin{tabular}{|c|c|c|c|}
\hline \multirow[b]{2}{*}{ Characteristic } & $\begin{array}{l}\text { Control } \\
(n=103)\end{array}$ & $\begin{array}{l}\text { Iron-fortified rice } \\
\quad(n=98)\end{array}$ & \multirow[b]{2}{*}{$p^{a}$} \\
\hline & \multicolumn{2}{|c|}{ Mean $(95 \% \mathrm{CI})$} & \\
\hline Age $-y r$ & $29.6(27.8-31.3)$ & $30.4(28.6-32.2)$ & .502 \\
\hline Hemoglobin-g/dL & $13.0(12.8-13.3)$ & $13.1(12.9-13.4)$ & .527 \\
\hline Plasma ferritin $-\mu \mathrm{g} / \mathrm{L}^{b, c}$ & $19.2(15.7-23.4)$ & $18.1(14.7-22.2)$ & .673 \\
\hline Log plasma ferritin $-\mu \mathrm{g} / \mathrm{L}^{c}$ & $3.1(2.9-3.2)$ & $3.0(2.8-3.2)$ & .673 \\
\hline Plasma transferrin receptors $-\mathrm{mg} / \mathrm{L}^{b}$ & $3.4(3.1-3.7)$ & $3.5(3.2-3.8)$ & .589 \\
\hline Body iron stores $-\mathrm{mg} / \mathrm{kg}$ body weight ${ }^{\mathrm{c}}$ & $4.8(3.8-5.7)$ & $4.5(3.5-5.4)$ & .643 \\
\hline C-reactive protein $-\mathrm{mg} / \mathrm{L}^{b}$ & $1.6(1.3-2.1)$ & $1.5(1.1-1.9)$ & .547 \\
\hline
\end{tabular}

a. P-value of analysis of variance (ANOVA) between groups.

$b$. Data were log-transformed for analysis. Means and confidence intervals derived from the log-transformed data were reverse-transformed for presentation.

c. Data points for subjects with elevated C-reactive protein were removed (control, $n=7$; iron-fortified group, $n=7$ ). 


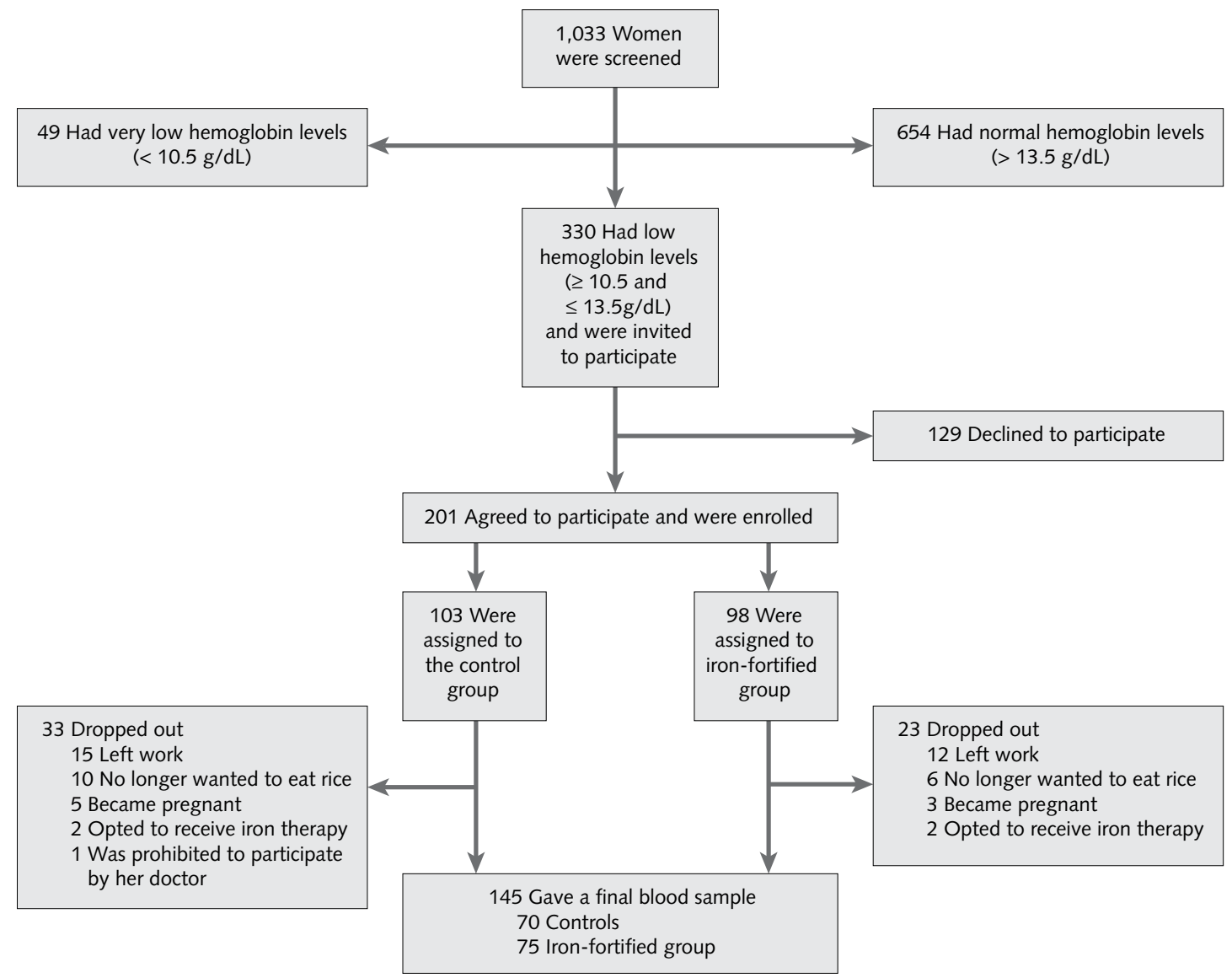

FIG. 1. Schema illustrating numbers of participants, exclusions, and dropouts

indicator was also significant in the model ( $p=.002$ to $p<.001)$, so in each case baseline status was included as a cofactor in the analysis. In the group that received iron-fortified rice, final plasma ferritin concentration and estimated body iron stores were significantly greater and transferrin receptor concentration was significantly lower than in the control group (table 2). Hemoglobin concentration was greater in the ironfortified group than in the control group, but the difference did not reach statistical significance $(p=.069)$. Nonetheless, when the analysis was restricted to those with baseline hemoglobin concentration $<12.8 \mathrm{~g} / \mathrm{dL}$, the difference was significant $(p=.048)$.

On the basis of daily records of the amount of rice served and left over, the mean \pm SD intake of prepared rice was $11.7 \pm 3.4 \mathrm{~kg}$ in the iron-fortified group and $12.1 \pm 3.5 \mathrm{~kg}$ in the control group (difference nonsignificant, $p=.443$ ), whereas the maximum intended intake was approximately $18.8 \mathrm{~kg}$. Likewise, the estimated total intake of iron from the fortificant in the ironfortified group was $1.56 \pm 0.48 \mathrm{~g}$, ranging from 0.17 to $2.44 \mathrm{~g}$. To take this wide variation into account, we repeated the outcome analyses using iron intake from fortificant as a covariable rather than using control versus iron-fortified group as a random factor, but the overall results did not change. Among women in the iron-fortified rice group, the intake of iron fortificant was a significant covariate for change in iron stores $(p=.018)$ when baseline body iron stores were controlled for. This relationship was compared graphically for the control and iron-fortified rice groups (fig. 2). The nonfortified rice in cooked form was assumed to contain $0.002 \mathrm{mg}$ iron/g. In the iron-fortified group, $19 \%$ of the women had a change in body iron stores that was below zero, whereas in the control group, $43 \%$ had a negative change.

The prevalence rates of anemia and iron deficiency were compared according to group and time point (fig. 3). In the group that received iron-fortified rice, there was an $80 \%$ reduction in the prevalence of anemia and a $29 \%$ reduction in the prevalence of iron deficiency. These reductions were statistically significant when tested by logistic regression with control for baseline prevalence. In contrast, there was no statistically significant difference between baseline and postintervention in the prevalence of anemia or iron 
TABLE 2. Postintervention comparison of biochemical indicators for Mexican women participating in a randomized, controlled efficacy trial of iron-fortified rice ${ }^{a}$

\begin{tabular}{|c|c|c|c|}
\hline \multirow[b]{2}{*}{ Indicator } & $\begin{array}{l}\text { Control } \\
(n=70)\end{array}$ & $\begin{array}{l}\text { Iron-fortified rice } \\
\qquad(n=75)\end{array}$ & \multirow[b]{2}{*}{$p^{b}$} \\
\hline & \multicolumn{2}{|c|}{ Adjusted mean (95\% CI) } & \\
\hline Hemoglobin-g/dL & & & \\
\hline All subjects & $13.8(13.5-14.1)$ & $14.2(13.9-14.4)$ & .069 \\
\hline Baseline hemoglobin $<12.8 \mathrm{~g} / \mathrm{dL}$ & $\begin{array}{c}12.6(12.1-13.1) \\
(n=28)\end{array}$ & $\begin{array}{c}13.3(12.8-13.8) \\
(n=27)\end{array}$ & .048 \\
\hline Plasma ferritin $-\mu \mathrm{g} / \mathrm{L}^{c, d}$ & $21.7(19.0-24.9)$ & $27.0(23.7-30.7)$ & .023 \\
\hline Plasma transferrin receptors $-\mathrm{mg} / \mathrm{L}^{\mathrm{c}}$ & $3.4(3.2-3.7)$ & $3.1(2.9-3.3)$ & .022 \\
\hline Body iron stores, $\mathrm{mg} / \mathrm{kg}$ body weight ${ }^{d}$ & $5.3(4.7-5.8)$ & $6.4(5.8-6.9)$ & .006 \\
\hline
\end{tabular}

a. Group differences were tested by analysis of covariance (ANCOVA), where the postintervention value of each biochemical indicator was the dependent variable and the baseline value for the same indicator was included as a covariable.

b. $P$-value of analysis of covariance (ANCOVA) between groups.

c. Data were log-transformed for analyses. Adjusted means (95\% confidence intervals) were reverse-transformed to original units for presentation.

d. Data for subjects with elevated C-reactive protein at baseline and/or postintervention were removed (control, $n=10$; iron-fortified group, $n=7$ ).

deficiency in the control group. For the comparison of group effect at baseline, there was no significant difference in the prevalence of anemia or iron deficiency between groups when the analysis was restricted to subjects with postintervention data. The absolute change, calculated as the change in prevalence in the iron-fortified group minus the change in prevalence in the control group, was 10.3 percentage points for anemia and 15.1 percentage points for iron deficiency. Overall, $62 \%$ of anemia was associated with iron deficiency. The prevalence of iron-deficiency anemia was reduced by 8.5 percentage points in the control group and by 14.7 percentage points in the iron-fortified group; thus, an absolute reduction of 6.2 percentage points in iron-deficiency anemia may be attributed to the intervention.

\section{Discussion}

Iron status was significantly improved among Mexican women who consumed about five meals per week of iron-fortified rice for a period of 6 months. This was demonstrated by a significant increase in plasma ferritin concentration and estimated body iron stores and a significant decrease in plasma transferrin receptor concentration in the group that received iron-fortified rice. Hemoglobin concentrations also increased in the ironfortified rice group, but this result was only statistically significant when the analysis was restricted to women with lower initial hemoglobin $(<12.8 \mathrm{~g} / \mathrm{dL})$. Further, the prevalence of anemia and iron deficiency was significantly lower postintervention than at baseline in the iron-fortified group, but not in the control group.

The SunActive form of iron used in this study had previously been shown to have relatively high bioavail-

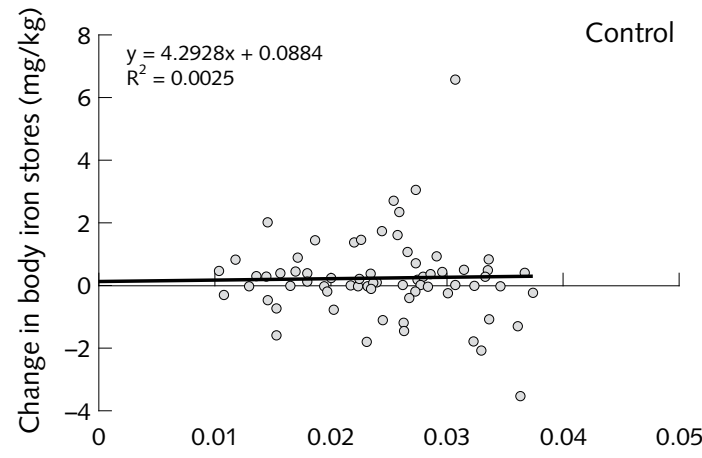

Total iron intake from rice during intervention $(\mathrm{g})$

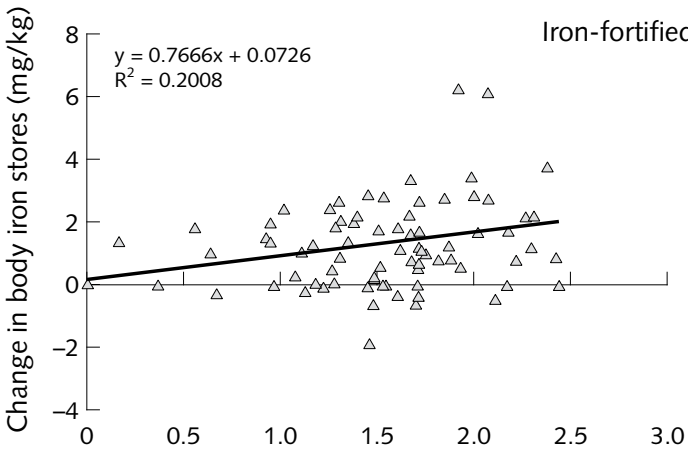

Total iron intake from rice during intervention $(\mathrm{g})$

FIG. 2. Change in body iron stores according to the intake of fortificant iron from rice provided by the intervention study for 6 months in the control group (top panel) and the ironfortified rice group (lower panel). For the control group it is assumed that cooked rice contained on average $0.002 \mathrm{mg}$ iron/g. Data points are adjusted for baseline iron stores. 


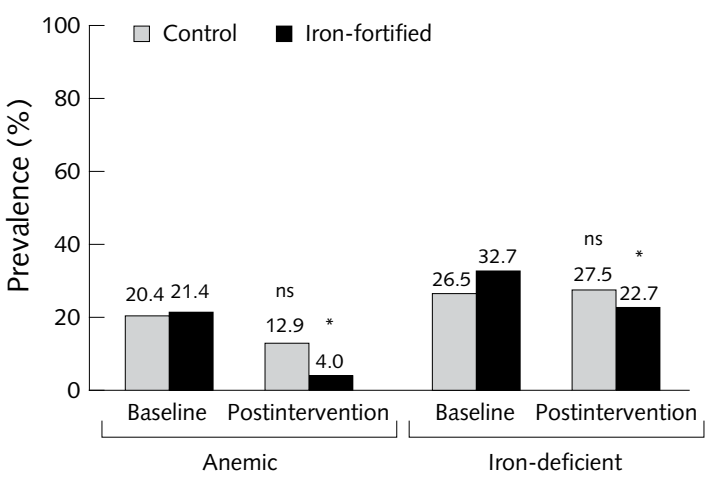

FIG. 3. Comparison of the prevalence of anemia (hemoglobin $<12.2 \mathrm{~g} / \mathrm{dL}$ ) and iron deficiency (serum ferritin $<12.0 \mu \mathrm{g} / \mathrm{L}$ or serum transferrin receptors $>8.5 \mathrm{mg} / \mathrm{L}$ ). Prevalence rates were determined from cases for which both baseline and postintervention data were available (for anemic subjects, control $n=70$ and iron-fortified $n=75$; for iron-deficient subjects, control $n=60$ and iron-fortified $n=68$ ). Statistical comparisons of between-group, postintervention prevalence rates used logistic regression controlled for baseline prevalence of the corresponding indicator $\left({ }^{*} p<.05\right.$; ns, nonsignificant).

ability, comparable to that of ferrous sulfate [15]. A hemoglobin repletion study conducted in rats indicated that a lower particle size of ferric pyrophosphate, as achieved through the kind of micronization used in SunActive, resulted in a greater relative bioavailability [13]. In the same study it was found that encapsulation of ferric pyrophosphate with fully hydrogenated palm oil and lecithin at a capsule:substrate ratio of 60:40 resulted in lower relative bioavailability. However, this is not identical to the microencapsulation formula used in SunActive iron (dextrin, glycerol esters of fatty acids, and enzymatically hydrolyzed lecithin).

More recently it has been shown that the food matrix affects the relative bioavailability of this form of iron [16]. Whereas in the study by Fidler et al. [15] the bioavailability of micronized, microencapsulated ferric pyrophosphate was $82 \%$ and $92 \%$ of that of ferrous sulfate when added to a wheat- and milk-based infant cereal and a yogurt drink, respectively, the bioavailability relative to that of ferrous sulfate was found by Moretti et al. [16] to be only $15 \%$ from a test meal of rice and vegetables and $24 \%$ from extruded rice dried into artificial grains. Further, the latter study also demonstrated that in addition to the absolute iron absorption, the relative bioavailability of ferric pyrophosphate also varied with iron status [16]. Prediction of the relative bioavailability of ferric pyrophosphate forms for use in food fortification has been difficult, given the large number of variables that affect it. The geometric mean absorption of iron from the latter test meal was 3.0\%. Even at this low level of absorption, the additional $13.4 \mathrm{mg}$ of iron per day ingested from the iron-fortified rice in our study would have provided approximately $0.40 \mathrm{mg} /$ day of absorbed iron, which is equivalent to about one-quarter to one-third of the daily requirement for nonpregnant, premenopausal, adult women $[21,27]$. Thus, even if absorption was only $3 \%$, it is not surprising that a significant increase in iron stores was observed in our study.

Moretti et al. [19] fed Indian schoolchildren about the same amount of iron as micronized ferric pyrophosphate with a mean particle size of $2.5 \mu \mathrm{m}$ in fortified rice $(20 \mathrm{mg}$ per meal, resulting in $13 \mathrm{mg}$ of iron actually consumed per school day) as we gave to the women in the present study $(20 \mathrm{mg}$ per meal, resulting in $13 \mathrm{mg}$ of fortificant iron actually consumed per work day), although the Indian study continued for 7 months, versus 6 months in the present study. But whereas the baseline body iron stores in the present study were about $4.65 \mathrm{mg} / \mathrm{kg}$ body weight, those in the Indian children were only about $1.05 \mathrm{mg} / \mathrm{kg}$ body weight. This much lower baseline iron status would naturally lead to greater absorption of nonheme iron and could explain the larger net decrease in prevalence of iron deficiency observed (i.e., a 23 net percentage point decrease vs. an 11 net percentage point decrease in the present study). The similar outcomes in these studies suggest that adding microencapsulated, micronized ferric pyrophosphate to rice is also a viable strategy for prevention of iron deficiency among rice-consuming populations. However, whether one compound type has a greater biological value than the other would need to be determined by making a direct comparison in human studies.

This intervention had a major impact on the prevalence of anemia and iron deficiency. The prevalence of anemia was reduced by $80 \%$. We observed an absolute change of 10.3 percentage points in anemia and 15.1 percentage points in iron deficiency. Mei et al. [24] recently reviewed the impact of iron interventions on various iron-status indicators. They considered that reductions in prevalences of anemia or iron deficiency of more than 10 percentage points were noteworthy.

There was also a reduction in the prevalence of anemia, but not iron deficiency, in the control group, but this was not statistically significant (fig. 3). It is possible that there were dietary changes that led to a reduction in the severity of anemia over the course of the intervention; since the women knew that the project was about iron nutrition, it is possible that some altered their dietary intakes to include more sources of bioavailable iron. In both the control and the iron-fortified group, some of the reduction in anemia occurred among anemic women without iron deficiency, so other causes of change cannot be ruled out. Nonetheless, net reduction in both anemia and iron deficiency was greater, and significant, in the iron-fortified group.

Trials among nonpregnant women often vary in their baseline prevalence of iron status, so that the 
magnitude of the response is rarely directly comparable among them. However, in an effectiveness study in Vietnam using NaFeEDTA-fortified fish sauce [28], the baseline prevalence rates of anemia (19.1\% to $26.3 \%)$ and of iron deficiency based on serum ferritin $(23.8 \%$ to $28.7 \%$ ) were similar to those in our study. The Vietnamese researchers observed an absolute reduction of 20 percentage points in the prevalence of anemia and of 15 percentage points in the percentage of low serum ferritin; the latter reduction was comparable to that observed in our study. Although the Vietnamese trial delivered on average a lower daily amount of iron $(7.5 \mathrm{mg} /$ day as compared with about $13 \mathrm{mg} /$ day in the present study), the intervention lasted much longer (18 months as compared with 6 months in the present study).

The portion of cooked rice served in this study $(210$ $\mathrm{g}$ for the first 3 months and $105 \mathrm{~g}$ for the second 3 months) was larger than the average portion typically consumed in Mexico (approximately 50 to $60 \mathrm{~g}$ of cooked rice). For this reason, the average actual daily intake of rice, and hence of iron derived from the ironfortified rice, was only about $63 \%$ of what the study was designed to deliver. In addition to differences in individual preferences, the wide variation in adherence to the intervention was attributed to differences in time away due to vacation or sick leave, unexpected changes in work shifts or work location that made the rice unavailable on some days, and early withdrawal of some women from the study. Low adherence to the intervention was apparently not due to adverse organoleptic changes caused by addition of the fortificant, because the rates of rice intake and dropouts due to women not wanting to eat so much rice were not different in the control and iron-fortified groups. Early in the study, some women in one of the factories reported having headaches, but the numbers of these women were evenly divided between the two groups and resulted in no dropouts. There were no other reports of adverse effects.

Despite low adherence, the iron-fortified rice provided an average of $13.4 \mathrm{mg}$ of iron/day, or about twothirds of the Mexican recommended daily intake (21 $\mathrm{mg} /$ day, assuming $7.5 \%$ bioavailability) [21] and was found to be efficacious even without controlling for intake of iron fortificant.

This study is somewhat limited in that we did not determine what the participating women's usual total dietary iron intakes were during the intervention and therefore could not control for differences in iron intake from foods other than the rice provided by the study. Data from the National Nutrition Survey of
Mexico in 1999 reported that the median iron intake by women in the central region of Mexico was $8.4 \mathrm{mg} /$ day (interquartile range, 6.1 to $11.2 \mathrm{mg} /$ day) [29]. If intakes from the women in these urban to semirural areas of central Mexico were similar to this, it is conceivable that the additional $13 \mathrm{mg}$ /day of iron provided by the intervention may have nearly doubled their iron intake. Indeed, in the iron-fortified group, a dose-response effect was observed between iron intake from the rice consumed and change in iron stores (fig. 2), an effect that was absent in the control group. Therefore, it is highly plausible that consumption of the fortified rice was responsible for the observed changes in iron status.

According to the results of the 1999 Mexican National Nutrition Survey, an average of $40 \%$ of nonpregnant Mexican women are iron deficient [30] and 20\% are anemic [31]. Although several programs have been introduced in Mexico to control the high prevalence of iron deficiency, these are largely directed to lowincome populations, and it has been suggested that complementary programs be developed to assist in increasing coverage. The median daily consumption of cooked rice in Mexico is only approximately 50 to $60 \mathrm{~g}$. Thus, in Mexico rice fortification alone would not be able to address public health nutrition problems. However, as Imhoff-Kunsch et al. [32] point out in the case of Guatemala, fortification is a relatively straightforward, cost-effective, and sustainable strategy, and therefore even grains consumed at such levels should be fortified.

Our results indicate that Ultra Rice fortified with microencapsulated, micronized ferric pyrophosphate is an efficacious means of improving iron status among women. This product should be further tested in other rice-consuming populations for both efficacy in improving iron status and consumer acceptability. The efficacy of this technology to improve vitamin A and vitamin E status has also been demonstrated [10]. Further steps should be taken to evaluate the potential effectiveness of Ultra Rice in large-scale micronutrient programs. Its use in targeted micronutrient programs, such as emergency feeding, and in school-feeding or other food security programs could also be considered.

\section{Acknowledgments}

Supported by a subcontract grant (GAT0004-01694CRT) from PATH through an original grant by the Bill and Melinda Gates Foundation. 


\section{References}

1. De Maeyer EM. Preventing and controlling iron deficiency anaemia through primary health care. A guide for health administrators and programme managers. Geneva: World Health Organization, 1989.

2. Pollitt E. Effects of a diet deficient in iron on the growth and development of preschool and school-age children. Food Nutr Bull 1991;13:110-8.

3. Walter T, Arredondo S, Arevalo M, Stekel A. Effect of iron therapy on phagocytosis and bactericidal activity in neutrophils of iron deficient infants. Am J Clin Nutr 1986;44:877-82.

4. Kruger M, Badenhorts CJ, Manswelt EPG, Laubscher JA, Spinnler Benadé AJ. Effects of iron fortification in a school feeding scheme and anthelmintic therapy on the iron status and growth of six- to eight-year-old schoolchildren. Food Nutr Bull 1996;17:11-21.

5. Rowland TW, Disroth MB, Green GM, Kelleher JF. The effect of iron therapy on the exercise capacity of non anemic iron-deficient adolescent runners. Am J Dis Child 1988;142:165-9.

6. Garn SF, Ridella SA, Petzold AS, Falkner F. Maternal hematologic levels and pregnancy outcomes. Semin Perinatol 1981;5:155-62.

7. Ross J, Horton S. Economic consequences of iron deficiency. Ottawa: Micronutrient Initiative, 1998.

8. Flour Fortification Initiative. Wheat flour fortification: Current knowledge and practical applications. Summary report of an international technical workshop. Cuernavaca, Mexico: 2004. Available at: http://www.sph.emory. edu/wheatflour/CKPAFF/indexforFFI.htm. Accessed online 29 March 2008.

9. Mannar V, Boy Gallego E. Iron fortification: Country level experiences and lessons learned. J Nutr 2002; 132:856S-8S.

10. Haskell MJ, Pandey P, Graham JM, Person JM, Shrestha RK, Brown KH. Recovery from impaired dark adaptation in nightblind pregnant Nepali women who receive small daily doses of vitamin A as amaranth leaves, carrots, goat liver, vitamin A-fortified rice, or retinyl palmitate. Am J Clin Nutr 2005;81:461-71.

11. Consultor Apoyo. Ultra Rice organoleptic tests in Ecuador. Quito, Ecuador: Consultor Apoyo, 2003.

12. Moretti D, Lee T-C, Zimmermann MB, Nuessli J, Hurrell RF. Development and evaluation of iron-fortified extruded rice grains. J Food Sci 2005;70:S330-6.

13. Wegmüller R, Zimmermann MB, Moretti D, Arnold M, Langhans W, Hurrell RF. Particle size reduction and encapsulation affect the bioavailability of ferric pyrophosphate in rats. J Nutr 2004;134:3301-4.

14. Cook JD, Minnich V, Moore CV, Rasmussen A, Bradley WB, Finch CA. Absorption of fortification iron in bread. Am J Clin Nutr 1973;26:861-72.

15. Fidler MC, Walczyk T, Davidsson L, Zeder C, Sakaguchi N, Juneja LR, Hurrell RF. A micronised, dispersible ferric pyrophosphate with high relative bioavailability in man. Br J Nutr 2004;91:107-12.

16. Moretti D, Zimmermann MB, Wegmuller R, Walczyk T, Zeder C, Hurrell RF. Iron status and food matrix strongly affect the relative bioavailability of ferric pyrophosphate in humans. Am J Clin Nutr 2006;83:632-8.
17. Zimmermann MB, Wegmueller R, Zeder C, Chaouki N, Rohner F, Saissi M, Torresani T, Hurrell RF. Dual fortification of salt with iodine and micronized ferric pyrophosphate: A randomized, double-blind, controlled trial. Am J Clin Nutr 2004;80:952-9.

18. Wegmuller R, Camara F, Zimmermann MB, Adou P, Hurrell RF. Salt dual-fortified with iodine and micronized ground ferric pyrophosphate affects iron status but not hemoglobin in children in Cote d'Ivoire. J Nutr 2006;135:1814-20.

19. Moretti D, Zimmermann MB, Muthayya S, Thankachan P, Lee TC, Kurpad AV, Hurrell RF. Extruded rice fortified with micronized ground ferric pyrophosphate reduces iron deficiency in Indian schoolchildren: A double-blind randomized controlled trial. Am J Clin Nutr 2006;84:822-9.

20. Centers for Disease Control and Prevention. Criteria for anemia in children and childbearing-age women. Morb Mortal Wkly Rep 1989;38:400-4.

21. Rivera Dommarco J, Hotz C, Rodríguez Ramírez S, García-Guerra A, Peréz-Expósito AB, Martínez Salgado $\mathrm{H}$, González Unzaga MA. Iron. In: Bourges $\mathrm{H}$, Casanueva E, Rosado JL, eds. Nutrient intake recommendations for the Mexican population. Physiological basis. Vol 1. [Hierro. En: Recomendaciones de ingestión de nutrimentos para la población mexicana. bases fisiológicas] Mexico City: Editorial Médica Panamericana, SA de CV; 2005:245-64. (in Spanish)

22. Neufeld L, García-Guerra A, Sánchez-Francia D, Newton Sánchez O, Ramírez Villalobos MD, Rivera Dommarco J. Hemoglobin measured by Hemocue and a reference method in venous and capillary blood. Salud Publica Mex 2002;44:219-27.

23. World Health Organization. Iron deficiency anaemia: Assessment, prevention and control. A guide for programme managers. Document WHO/NHD/01.3. Geneva: WHO, 2001

24. Mei Z, Cogswell ME, Parvanta I, Lynch S, Beard JL, Stoltzfus RJ, Grummer-Strawn LM. Hemoglobin and ferritin are currently the most efficient indicators of population response to iron interventions: An analysis of nine randomized controlled trials. J Nutr 2005; 135:1974-80.

25. Cook JD, Flowers CH, Skikne BS. The quantitative assessment of body iron. Blood 2003;101:3359-64.

26. Thuy PV, Berger J, Davidsson L, Khan NC, Lam NT, Cook JD, Hurrell RF, Khoi HH. Regular consumption of NaFeEDTA-fortified fish sauce improves iron status and reduces the prevalence of anemia in anemic Vietnamese women. Am J Clin Nutr 2003;78:284-90.

27. Food and Nutrition Board, Institute of Medicine. Dietary reference intakes of vitamin $\mathrm{A}$, vitamin $\mathrm{K}$, arsenic, boron, chromium, copper, iodine, iron, manganese, molybdenum, nickel, silicon, vanadium, and zinc. Washington, DC: National Academy Press, 2002.

28. Thuy PV, Berger J, Nakanishi Y, Khan NC, Lynch S, Dixon P. The use of naFeEDTA-fortified fish sauce is an effective tool for controlling iron deficiency in women of childbearing age in rural Vietnam. J Nutr 2005;135: 2596-601. 
29. Barquera S, Rivera JA, Espinosa-Montero J, Safdie M, Campirano F, Monterrubio EA. Energy and nutrient consumption in Mexican women 12-49 years of age: Analysis of the National Nutrition Survey, 1999. Salud Publica Mex 2003:45:S530-9.

30. Villalpando S, García-Guerra A, Ramírez Silva CI, Mejía-Rodríguez F, Matute G, Shamah-Levy T, Rivera JA. Iron, zinc and iodide status in Mexican children under 12 years and women $12-49$ years of age. A proba- bilistic national survey. Salud Publica Mex 2003;45: S520-9.

31. Shamah-Levy T, Villalpando S, Rivera JA, MejíaRodríguez F, Camacho-Cisneros M, Monterrubio EA. Anemia in Mexican women: A public health problem. Salud Publica Mex 2003;45:S499-507.

32. Imhoff-Kunsch B, Flores R, Dary O, Martorell R. Wheat flour fortification is unlikely to benefit the neediest in Guatemala. J Nutr 2007;137:1017-22. 